\section{Southern Ontario}

\section{Two Forestry Pioneers Honoured in Norfolk County}

When the keynote speaker, Ken Armson, retired Chief Forester of Ontario, spoke to the celebrants of the $100^{\text {th }}$ anniversary of the St. Williams Forestry Station in 2008, the "Forest Capital of Canada," he suggested that, although the principal supporter of the establishment of the Station had received many honours, Dr. Edmund Zavitz had never had a forest named after him. Organizers of the event, the Port Rowan/South Walsingham Heritage Association took up the challenge. With the support of the St. Williams Conservation Reserve Citizens Advisory Council, the former "Nursery Tract" was dedicated to his memory. The Heritage Association canvassed many forestry and conservation organizations in the country and the response was very positive. Sufficient funds were raised to erect a suitable monument at the Forestry Station, not far from the grave of Colonel Arthur Pratt, MPP, and another principal in the establishment of the first Forestry Station in Canada.

The financial support also allowed the Heritage Association to relocate the plaque dedicating the "Turkey Point Tract" of the Conservation Reserve to Dr. J.H. White, a colleague and friend of Dr. Zavitz who had been honoured by the members of the Southern Ontario Section of the Canadian Institute of Forestry/Institut forestier du Canada and his students and colleagues at the Faculty of Forestry in Toronto in 1949. Since the establishment of the Turkey Point Park as part of the forest tract, his cairn had become almost hidden from public view and it had been deteriorating to the point where the plaque was likely to be stolen. A new monument was installed along the well-travelled "Turkey Point Road," across from the entrance to the park.

On August 14, during the local "Forest Fest" and in the presence of representatives of the Canadian Institute of Forestry/Institut forestier du Canada, the Ontario Professional Foresters

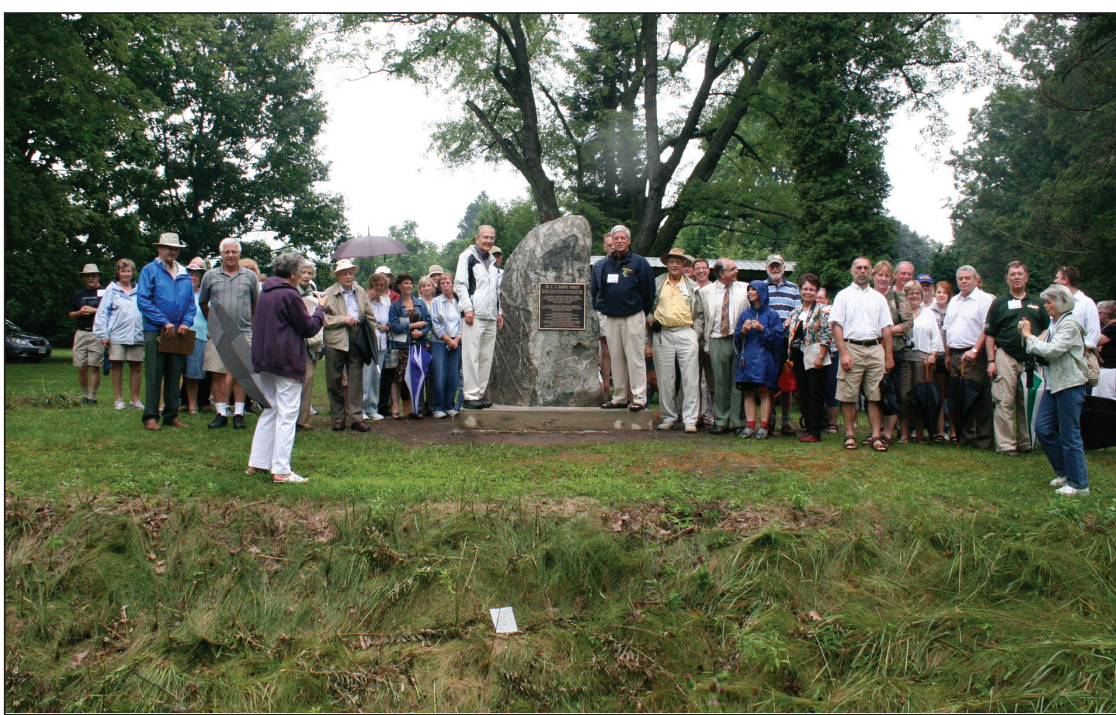

Peter and Sherman Zavitz flanking the new memorial in honour of E.J. Zavitz, surrounded by dignitaries and friends.

Association, The Canadian Forestry about a hundred interested citizens, the new plaque for Dr. Zavitz was unveiled by his grandson Peter Zavitz and his nephew Sherman Zavitz. An hour later the plaque to Dr. White was re-inaugurated by a great grand niece and nephew of Dr.White, Anna and Max Schramp. Dr. White's niece Janette White spoke of her uncle who had dedicated his life to the conservation of Ontario's natural Association, the County of Norfolk and

resources and the teaching of his students, setting high standards for himself and all who worked with him.

The two ceremonies were perfectly matched on the previous day by the launching of the biography of Dr. Zavitz, "The Father of Reforestation in Ontario" by Dr. John Bacher: "Two Billion Trees and Counting, the Legacy of Edmund Zavitz" (see book announcements). The launch took place at the "Forest Interpretive Centre" which is

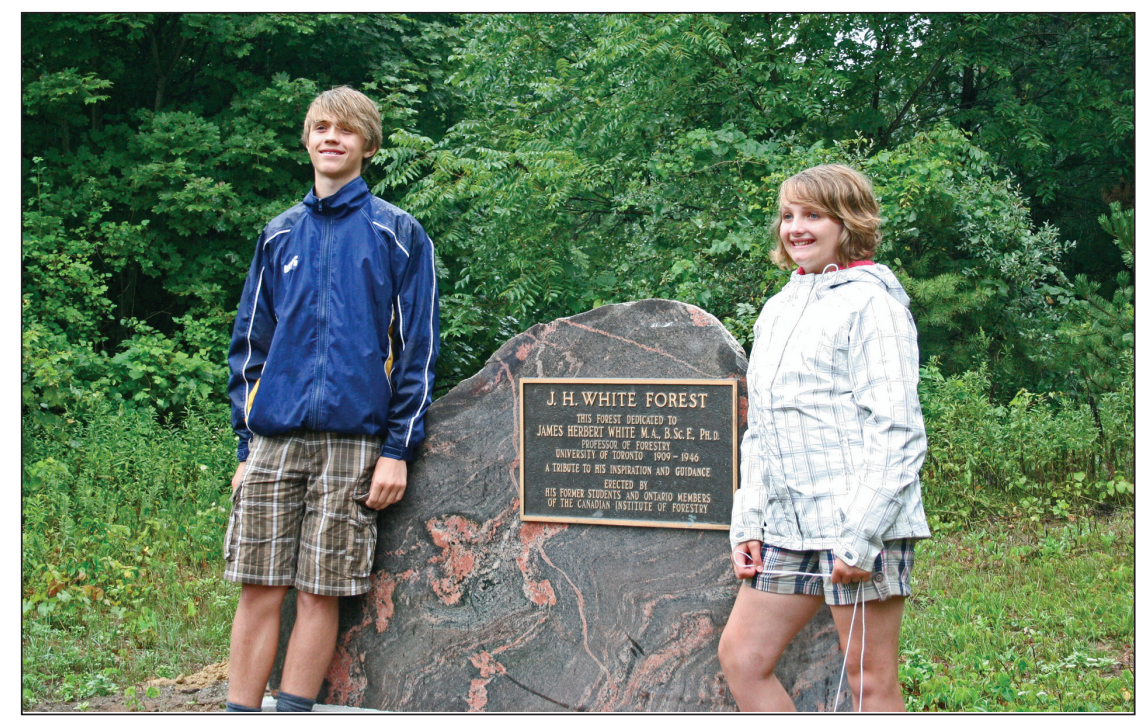

Great grand niece and nephew Anna and Max Schramp at the new White Memorial. 